\title{
Overcompensation as a service recovery strategy: the financial aspect of customers' extra effort
}

\author{
Zsofia Kenesei $^{1}$ (D) $\cdot$ Zsofia Bali $^{1}$
}

Received: 16 July 2019 / Accepted: 23 January 2020 / Published online: 6 February 2020

(c) The Author(s) 2020

\begin{abstract}
Compensation is one of the most important elements of service. Companies often pursue a strategy of overcompensation; however, there are contradictory results in the literature whether overcompensation has a positive or negative effect on postcomplaint customer behaviour. In this paper, based on three studies, we prove that examining the amount of additional effort required of the customer in order to achieve service recovery can help us better explain outcomes of the service recovery. Our results clearly show that the degree of additional customer effort has significant influence both on satisfaction and on perceived fairness and it moderates the effect of the amount of compensation.
\end{abstract}

Keywords Compensation · Consumer behaviour · Complaint handling ·

Satisfaction · Justice

\section{Introduction}

Service companies commit mistakes from time to time, which results in consumer loss. Such service failures lead to customer dissatisfaction and may create a complaint situation. A key element of the retention of disaffected customers is to implement an appropriate service recovery mechanism in order to enable the organization responsible for the flawed service to restore customer confidence. The determination of the appropriate level of compensation is a critical factor of efficient service recovery.

Service companies have various tools at their disposal to redress the losses at the core of the complaint situation. One option is to offer a level of compensation which exceeds the loss suffered: in other words, overcompensation. For organizations, it is

Zsofia Kenesei

zsofia.kenesei@uni-corvinus.hu

Zsofia Bali

balizsofiaa@gmail.com

1 Corvinus University Budapest, Fővám tér 8, 1093 Budapest, Hungary 
crucial to understand under exactly what circumstances customers actually expect to receive extra compensation in addition to the correction of the flawed service, and what kind of effect such overcompensation is likely to have on postcomplaint customer behaviour. While at first sight, it may appear evident that postcomplaint customer satisfaction has a linear relationship with the level of compensation offered, the theory of justice in fact predicts that this is not necessarily the case. This contradiction is reflected in the findings of the available literature, where various authors have often presented contradictory results. While some studies have found that overcompensation can help organizations regain customer satisfaction (Noone and Lee 2011; Noone 2012; Crisafulli and Singh 2016), others have argued that overcompensation in fact offends customers' sense of justice and may result in dissatisfaction with the service recovery process (Haesevoets et al. 2014, 2017).

The goal of our research is to identify the factors which underlie these apparently conflicting findings and to develop and test a theoretical framework which can explain the full spectrum of observed customer reactions to overcompensation. Based on a qualitative inquiry we argue that the extra effort customers have to shoulder in order to be provided service correction by the organization responsible for the flawed service is a major predictor of satisfaction and fairness perception. In addition to this, we also identify whether the form of monetary compensation influences postcomplaint customer satisfaction.

Our paper is structured as follows. First, we discuss previous studies on the effects of monetary compensation, using the theoretical framework of justice. We will address the various factors that might influence satisfaction with the different forms of compensation, and we will also evaluate the existing findings on the effects of overcompensation. In the second half of our paper, we introduce our research model, which was created based on the findings of prior qualitative interviews. In order to test our hypotheses, we conducted two scenario-based experiments. After the description of the method and presentation of our results, we discuss the theoretical and managerial implications of our findings which will be especially relevant for service companies.

\section{Theoretical background}

A complaint situation inevitably signals customer dissatisfaction, and organizations need to establish a professional service recovery mechanism in order to turn this dissatisfaction into postcomplaint customer satisfaction. If customers who suffered a loss as a result of a service failure are not compensated appropriately, they will remain dissatisfied and they will be unlikely to continue to accept the services offered by the organization. In addition to this, insufficiently compensated customers may share their negative experiences within their social circles, which can lead to widespread damage to the reputation of the services offered by the organization, and further loss of actual and potential customers and a consequent fall in revenues and profits. 
Service recovery is usually examined within the framework of the theory of justice, where three factors are identified which determine whether the complainthandling process will be perceived as appropriate by the customer.

\subsection{Theory of justice and service recovery}

The level and type of compensation, the service recovery procedure itself and the behaviour of the organization's representatives vis-à-vis the customer all influence the perceived fairness of a service recovery offer in a flawed service situation (Tax et al. 1998). Based on this, three dimensions of justice can be identified in a service recovery situation: distributive justice, procedural justice and interactional justice (Smith et al. 1999; Maxham 2001; McCall-Kennedy and Sparks 2003; McCollough et al. 2000). Procedural justice refers to the fairness of protocols and events within the recovery process, interactional justice is related to the communication and general behaviour of the organization's representatives, while distributive justice is a function of the perceived fairness of the level of compensation. In the last dimension, the customer compares the losses suffered because of service failure with the income earned from the compensation. If customers perceive the proportion of losses and incomes to be appropriate, then they will regard the relationship between the organization and themselves as just, whereas if they perceive this proportion inappropriate, they will experience a lack of justice (Blodgett et al. 1997; del Rio-Lanza et al. 2009; Choi and Choi 2014). Perceived fairness leads to higher postcomplaint satisfaction that enhances customer engagement (Cambra-Fierro et al. 2016). As Mannaa and Chaudhry (2013) point out, service failures are often impossible to correct, and in such cases, empathy and politeness are crucial factors in retaining the commitment and loyalty of the consumers affected by the service failure. In general, interactional justice (Chen and Lee 2018) or procedural justice (Cheung and To 2017) often serves to compensate for an inadequate level of distributive justice. As Davidow (2003) points out, the perception of justice is influenced most strongly by the following three factors: equality, need and equity. The principle of equality emphasizes the equality of outcomes: a service recovery process is fair if customers affected by the same service failure receive the same treatment. The principle of need takes the needs of affected customers as a reference point. Davidow (2003) uses the example of the scarcity of available seats on an alternative airline in case of a cancellation: the limited number of available seats will be given to those customers who are most in need of getting to their intended destination. In the study of distributive justice, the principle of equity is crucial. Customers perceive a service recovery process equitable if their losses (including the time and effort expended lodging a complaint and participating in the service recovery process) are not greater than the compensation (such as refunds or discounts) received. (Roschk and Gelbrich 2014; Crisafulli and Singh 2016; Blodgett et al. 1997).

The focus of our paper is distributive justice and more specifically the effects of overcompensation on postcomplaint customer behaviour. 


\subsection{The role of compensation}

Compensation can be defined as a tangible benefit provided by organizations to disaffected customers (Davidow 2003; Gelbrich et al. 2015). Standop and Grunwald (2009) have shown that the appropriate form and level of compensation are crucial: they pointed out that postcomplaint customer satisfaction can actually be higher than the satisfaction of those customers who did not have any negative experience with the service or organization due to service failure in the first place. In order to redress the negative experience of disaffected customers, the service failure needs to be corrected. In order to mitigate the tangible and intangible losses suffered by the customers, organizations provide compensation to them. (Blodgett et al. 1997). There are two types of compensation in case of service failure: tangible (material) compensation and intangible (psychological) compensation. The former includes compensation that can be expressed in financial terms, whereas the latter covers compensation of a less tangible and more emotional nature (Gelbrich and Roschk 2011). Money back, vouchers, store credits, new/exchanged goods and new/reperformed service are examples of tangible compensation; whereas empathy and sincere apology are elements of psychological compensation (Roschk and Gelbrich 2014). The importance of intangible compensation is well-illustrated by complaint situations arising from inappropriate employee behaviour toward a customer, in the course of which the customer suffers emotional loss, and as a consequence, psychological compensation plays a key role. Compensation of this kind contributes to the preservation of the self-esteem of the affected customer and to the maintenance of a long-term relationship between the organization and the customer (Standop and Grunwald 2009; Gelbrich et al. 2016).

\subsection{Different levels of material compensation}

The amount of compensation offered to address customer losses arising from service failure does not always correspond to the costs incurred by the disaffected customer as a result of the failure. The level of compensation is affected by various factors. Prior experiences of the customer, the communication strategy of the organization, the compensations already offered to other affected customers and the magnitude of the loss suffered by the client all influence the acceptable level of compensation (Maxham III and Netemeyer 2002). The customers affected by service failure suffer losses as a result, and the expected level of compensation should be in relationship with the level of these: this means that at the very least, the organization has to restore the situation that preceded the service failure event; otherwise, customers may become unsatisfied. Based on the equity paradigm, the higher the losses, the higher is the compensation demanded by the affected customers in order to balance the losses suffered as a result of service failure. (Kim and Ulgado 2012; Davidow 2003). Compensation is usually defined as a percentage of the customer loss; thus, one can speak of partial compensation, full compensation, and overcompensation (Gelbrich et al. 2015). 
In the case of partial compensation, the compensation provided by the organization is less than the loss suffered by the customer. Partial compensation typically occurs in cases where customers eventually accepted the flawed service, but they were still dissatisfied with a certain component of the service. E.g., in the case of significant delays, train companies typically reimburse clients only partially, even though the service they provided was in essence flawed.

Full compensation means a level of compensation equal to the level of customer loss. Full compensation enables an organization to address service failure by essentially restoring the pre-failure situation. However, in practice, organizations often fall short of providing compensation for all the losses suffered by a client. (Gelbrich et al. 2015; Gelbrich and Roschk 2011). In fact, simply reimbursing customers the full purchase price may not be enough to satisfy them, as in addition to losing the service, they may have incurred other costs. In such cases, full reimbursement of the purchase price may be seen as not amounting to full compensation. A typical situation is a flight cancellation, where even though the price of the air ticket itself is reimbursed, but other losses, such as the loss incurred by being unable to arrive to one's pre-booked and pre-paid accommodation on time, are not addressed. Often, the mere act of lodging a complaint incurs material and psychological costs. Because of this, in practice, full compensation typically means a compensation level significantly higher than the simple reimbursement of the purchase price. (Haesevoets et al. 2017).

This practice is described as overcompensation, i.e. the offering of a compensation level which exceeds the original purchase price in service failure situation. In other words, overcompensation offers a level of compensation that is higher than the direct losses suffered by the customer. (Haesevoets et al. 2017; Noone and Lee 2011; Noone 2012; Crisafulli and Singh 2016).

Compared to full compensation, overcompensation is a costlier alternative from the perspective of the organization, since it involves providing compensation higher than full compensation; by the same token, overcompensation is a more rewarding alternative from the perspective of the customer. Companies naturally try to keep service recovery costs as low as possible: this means that unless the benefits of overcompensation are significantly higher than the benefits of the alternatives, it makes sense in general to prefer less costly strategies such as full compensation or partial compensation (Noone 2012).

\subsection{Psychological and economic aspects of overcompensation}

While prior to compensation, customers experience a state of disadvantageous inequality arising from service failure; after an episode of overcompensation, customers experience a state of advantageous inequality. Research into fairness has shown that customers prefer advantageous inequality to disadvantageous inequality. However, it is less clear whether customers in general prefer a compensation scheme that creates a state of advantageous inequality to one that would create a state of equality (Garrett 1999). Customer reactions to various compensation schemes might be examined from two perspectives: the psychological and the economic (Haesevoets et al. 2014). 
The psychological perspective emphasizes that it is not only the absolute magnitude of the compensation that matters: the perceived fairness of the compensation and its appropriate proportionality with the losses also influences postcomplaint customer behaviour. One reflection of this is that in general, customers prefer compensation schemes which restore equality to those which lead to inequality (even if that inequality is actually advantageous to the consumer): in other words, customers often prefer full compensation to overcompensation (Chen et al. 2018). Crisafulli and Singh (2016) argue that this apparent paradox is explained by the fact that customers want to avoid the feeling of guilt which would arise if they were to become beneficiaries of an unjust situation.

However, the findings of some studies in fact contradict these predictions of the psychological approach. The authors of these papers argue that customers have a higher level of satisfaction after overcompensation (which leads to a state of advantageous inequality) than after full or partial compensation (which leads a state of equality). This predicts that raising the level of compensation will lead to higher postcomplaint customer satisfaction (Garrett 1999).

These observations resonate with the economic perspective, which emphasizes financial gain as a primary motivator of humans and stresses the desire of maximalizing financial outcomes. In this view, overcompensation is a superior outcome in monetary terms, and therefore, it is likely to result in higher postcomplaint satisfaction, increased repurchase intention, a more positive company image, and stronger loyalty.

\subsection{Effect of overcompensation and its moderators}

Although there is a controversy about the exact effect of overcompensation, there is set of factors that researchers found to be important to consider in examining this effect. Based on a research that compared different levels of overcompensation, Gelbrich et al. (2015) found that the relationship between the amount of overcompensation and satisfaction is not linear. There is a downward slope for higher amount of overcompensation for customers who rejected the flawed service and a saturation effect for customers who accepted the service. They recommended a maximum of $170 \%$ overcompensation, as above this amount the satisfaction may decrease. They also found that there can be a difference between the type of services, as the slope and maximum satisfaction were different in the case of lodging and a music theatre.

Haesoevets et al. (2017) similarly claimed that there is an inverted U-relation between the amount of overcompensation and loyalty but found two distinct customer groups: while the first group has rejected any overcompensation (downstream??? curve), the second has accepted it and their loyalty increased gradually until a certain point (flattening curve). In the study, more than $80 \%$ of the respondents showed this letter pattern. Based on three studies, they recommend an overcompensation of $150 \%$ as the optimal level.

Another factor that can influence the relationship between the amount of overcompensation and satisfaction is the relationship quality between the customer and the service provider (Gelbrich et al. 2016; Tektas 2017). While for customers with a 
low relationship quality, the shape of the curve remains inverted $U$ shape; in case of high relationship quality customers, the curve is close to linear; and at $200 \%$ overcompensation, it does not reach saturation. Based on the evaluation of the authors, this higher amount of overcompensation stands for the appreciation of the trust and loyalty of the high relationship customers.

Estelami and Meyer (2002) found that overgenerosity is not valued by customers especially if it is provided by a low-level service provider. In this case, customers would feel ashamed or think that the employee risks the profitability of the business. On the other hand, overgenerosity is received more favourably by customers if it is provided by a high organizational-level service provider. This relationship is moderated by past purchase history, i.e. if there is a longer relationship with the provider, customers are more willing to accept overgenerosity.

Noone (2012) claims first that 200\% overcompensation causes significantly higher justice perceptions than either full or partial compensation and that cashbased overcompensation is perceived fairer than credit-based (over)compensation. This final factor is worth further investigation.

\subsection{Different forms of compensation}

In addition to the level of compensation, its form is also an important determinant of postcomplaint customer satisfaction. Monetary compensation may be offered either at the time of the complaint or in a delayed fashion. Based on this, one can differentiate between cash-based and voucher-based compensation. One typical instance of cash-based compensation is a 'money back' scheme, whereas voucher-based schemes include cases where the customer receives a store credit which can be redeemed at the time of the next purchase. These two types of compensation differ significantly in terms of flexibility, timeliness and uncertainty (Roschk and Gelbrich 2014; Noone and Lee 2011; Noone 2012; Crisafulli and Singh 2016).

Timeliness refers to the actual time when the benefits connected to the compensation can be realized. In case of cash-based schemes, customers receive at once the compensation that they are entitled to as a consequence of service failure. Voucherbased compensation entails that customers can only realize the benefits at a later point in time, at the time of their next purchase at the same company (Zaubermann 2003). In terms of timeliness, customers in general prefer immediate compensation to delayed compensation. The second differentiating factor between cash-based and voucher-based compensation is uncertainty. In the case of cash-based compensation, customers can be certain that they will indeed receive the compensation, since it is immediately transferred to them. As opposed to this, in the case of voucherbased compensation, the actual event of receiving the compensation is placed in the future and it is thus uncertain. In general, customers prefer certain (immediate) compensation to uncertain (delayed) compensation. Flexibility is another important parameter. In the case of voucher-based compensation, the customers' options of realizing the benefits of the compensation are strictly limited as they are required to redeem the voucher by affecting another purchase at the same company. Cash-based 
compensation, on the other hand, imposes no such restrictions at all on the use of the compensation received.

Crisafulli and Singh (2016), as well as Noone and Lee (2011) have found that customers in general prefer cash-based compensation to voucher-based compensation. This is in line with the important benefits of cash-based compensation discussed above. Nevertheless, we would like to emphasize that voucher-based schemes do have a major advantage when it comes to repurchase intent. Noone and Lee (2011) point out that compared with the alternatives, voucher-based compensation has the highest positive effect on the probability of repurchase/repatronage. This is explained by the observation that customers are strongly motivated to restore fairness and equality, which, in the case of voucher-based compensation, can only be achieved if they redeem the voucher in an act of repurchase. This in turn gives the company a second chance to provide a high-quality service experience to the client and to increase postcomplaint client satisfaction. Tang et al. (2018) propose a more situation-based strategy, as they emphasize that different pairings of recovery timing and strategy should be employed adjusted to the state of emotion of customers.

To conclude, the overview of relevant research shows that it is far from evident that overcompensation after service failure affects satisfaction and loyalty in a positive way. While there are cases when overcompensation helps companies in the process of satisfactory service recovery (Gelbrich et al. 2015), in other cases it may hinder it (Haesoevets et al. 2014). Our goal in this paper is to explore the underlying reasons for these seemingly contradictory findings. To this end, we conducted a series of studies, which we discuss in the next section.

\section{Study 1: qualitative study on the role of customer effort}

The contradictory findings in the literature discussed above strongly suggest that there exist some hitherto unexamined factors that need to be built into our models in order to gain a more satisfactory understanding of the effects of overcompensation on postcomplaint customer satisfaction. Our goal in the exploratory research stage was to identify any additional factor which might help us better explain how customers react to overcompensation. Based on the findings of this stage, we are able to formulate our hypotheses that will serve as the basis for Study 2 and Study 3.

\subsection{Method and sample}

Throughout the process of data collection, coding and analysis, the methodology of grounded theory was followed. In addition to the two main schools of grounded theory (Strauss and Corbin 1990; Glaser 1992), constructivist grounded theory, 2014) has become popular in the past few years (Denzin and Lincoln 2011; Wertz et al. 2011). Contrary to the markedly positivist stance of the original grounded theory concept that objective knowledge of the world can be acquired, constructivist grounded theory claims that researchers are in continuous interaction with the process and the object of inquiry. A characteristic trait of the constructivist method is 
the recognition that researchers themselves are an important part of the process, as they continually interact with interviewees and data, and therefore, their personal input plays a significant role in the findings and the theory developed.

Based on these principles, we conducted semi-structured interviews, using predetermined, open-ended questions that enabled us to generate a theory after the coding and analysis of the data. The interviews were planned to cover two main topics. In the first part, we explored the expectations of our respondents regarding a service failure. In this phase, our inquiry was focused on the possible solutions and compensation expectations that can be satisfying in a situation where in addition to some compensation, there is a possibility of correcting the service failure. In the second phase, we presented scenarios asking their reactions to different failure scenarios and solutions. In this phase, we planned to collect aspects that can have an effect on their reactions.

In order to reach our goal, we conducted in-depth interviews with 10 subjects concerning their experiences with service recovery in connection with service failure. We designed our sample in accordance with the principles of theoretical sampling and continued until reaching saturation. Our respondents were selected with a snow-ball technique and we strived for heterogeneity in terms of age, gender and background.

\subsection{Data analysis and results}

The transcription of the interviews and the analysis of the transcripts were carried out by the authors. Throughout the process of data collection and analysis, we followed the basic principles of grounded theory, specifically the constant comparison technique. We iteratively collected and analysed data, comparing constantly the newly emerged data against the already existing insights (Charmaz 2000). Moving through the different levels of coding is a critical element in data analysis. In the first step, with the help of open coding, we identified keywords and key phrases. During this phase, we developed the first-order categories to describe the reaction of consumers to overcompensation. As a result, several conceptual groups having an impact on the perception of overcompensation have been distinguished. Firstlevel categories included phrases such as 'it cost me money', 'unpleasant feeling', 'it takes my time', 'they fix it right away', 'they ought to compensate me', 'it took me a lot of effort' or 'it is insignificant'. The next step of coding (axial coding) involves the classification and grouping of key phrases to create concepts such as 'additional time', 'additional money', 'compensation', 'additional effort' or 'insignificant additional effort'. After this, in the final step (selective coding), we identified the key concepts which will underpin our theory. This resulted in the creation of the following concepts: 'effort' and 'compensation'. After a while, the same key phrases and concepts repeated themselves, which we interpreted as a sign of saturation, and after this, we discontinued the further collection of data.

The first important finding of our analysis is that fundamentally, what customers expect is not compensation but, if it is possible, that the service provider provides (i.e. reperforms) the original service that they have paid for. 
What really matters to me is that the company corrects its mistake and does the job properly the second time. That's why I went to them in the first place. I don't need them to pay me my money back: I want them to do their job properly, that's what I payed them for! (man, age 27)

Furthermore, it became clear from the interviews that in addition to the actual direct material loss suffered as a consequence of service failure, there is another crucial factor which customers take into account when formulating their demand for compensation: the level of additional effort that they have to make in order to achieve service recovery.

Having kept me waiting for so long, I think I am now entitled to expect some degree of compensation. I think $15 \mathrm{~min}$ is about the limit after which some sort of compensation should be given in addition to fixing the error. Time is money, after all! (man, age 57)

Service acceptance vs. service rejection has been identified by Roschk and Gelbrich (2014) as a factor in the determination of the appropriate level of compensation: they found that consumers who decided to accept the flawed service find it difficult to identify a clear benchmark point to formulate the level of compensation that they demand. In our research, we added a new perspective to this: the question of service reperformance. In cases where the flawed service can be reperformed, our interviewees expressed a clear and strong preference for receiving the desired service rather than receiving their money back.

Let them fix their mistake, rather then giving me my money back! That's why I called them in the first place, to do their job properly. (man, age 43)

The further scrutiny of these issues revealed that in the case of reperformance, the level of the additional effort required from customers has a strong effect on the expected level of compensation. Note that effort as an antecedent of customer satisfaction with service recovery has so far been investigated only in the context of the company's employees (Cambra-Fierro et al. 2015), suggesting that greater recovery effort perceived by the customer leads higher satisfaction. Our research results indicate that effort can be interpreted on the side of the customer as well. If the correction of the service failure entails significant additional costs for the customer (whether of temporal, material or emotional nature), then most customers deem it appropriate or fair to receive overcompensation (i.e. compensation which exceeds the direct economic loss suffered). On the contrary, if any additional costs or efforts on the customers' side are marginal, then no compensation over the correct performance is expected in general.

I don't need any compensation. They fixed the mistake right away, so I suffered no loss whatsoever. (woman, age 26)

The additional efforts which customers need to make in order to achieve recovery of the flawed service are very often not of a directly monetary nature, but rather, of a temporal kind. Due to the wide variety of services, this can take many forms and we can only provide a handful of illustrative examples. Consider the case 
where a hotel room is unclean, and it needs to be cleaned: this means that the guest can only occupy the room a couple of hours later than originally intended. A hairdresser might fix the botched haircut: however, this means that the patron has to stay longer than planned. Internet providers may need to send a mechanic to the customer's home to fix an error: this means that the customer needs to stay at home. Service failure on part of a car mechanic may involve not fixing the car on time: this means that the customer may have to go back the next day to fetch the car. The practical implication of this is that in case of a service failure, service providers need to evaluate carefully the extra effort on the customer's side that a service reperformance or correction will involve; since this is the main factor in determining the expected level of compensation. The theoretical implication is that the study of the additional effort required from customers is essential in order to properly analyse customer behaviour in connection with overcompensation.

We would like to emphasize that the concept of additional customer effort introduced here is quite separate from the well-known concept of procedural justice (Wirtz and Mattila 2004). Procedural justice in the context of service recovery refers to the perceived fairness and justice experienced by the customer in the process of complaint handling and the attainment of compensation: this includes elements such as the time difference between lodging a complaint and receiving a compensation, or any problems which arise in the complaint registration process. The concept of additional customer effort, however, is not related to difficulties or problems arising within the process of service recovery. Rather, it is the inherent nature of service reperformance and compensation in itself which entails additional customer efforts, even in cases where the service recovery process of the organization is optimal and flawlessly executed.

\section{Research hypotheses}

Based on the literature review and the analysis of the interviews, we formulated our hypotheses around two broad themes: the additional customer effort required in service recovery and the form of compensation.

With our first hypothesis, we empirically test one of the findings from the qualitative research stage: in case of an outcome failure that can be corrected, customers in general prefer the appropriate reperformance of the service to receiving monetary compensation.

Roschk and Gelbrich (2014) have shown that in general, customers have the highest postcomplaint satisfaction if the type of compensation corresponds to the type of service failure. If the service is such that it can be reperformed, then in general, customers above all expect the organization to reperform the service in a flawless fashion. Our hypotheses, however, is that this is only true if customers are not required to make additional efforts in order to facilitate this service reperformance. In the light of this, our first hypothesis is the following: 
H1 If customers are not required to make significant additional efforts in connection with the service recovery, they will not require monetary compensation in addition to the satisfactory performance.

The exploratory research suggests that the degree of satisfaction with a compensation depends not only on the level of compensation, but also on the additional customer effort needed in order to attain the flawless service. Our second hypothesis concerns this connection between additional customer effort and postcomplaint satisfaction. Based on our analysis of the interviews, we assume that customers will have higher postcomplaint satisfaction if they are not required to make significant additional efforts in the course of the service recovery process. Gelbrich et al. (2016) argue that most customers wish to receive such recovery which leads to a state of equality. In the context of additional customer effort, this means that if customers are required to make significant additional efforts in order to receive a flawless reperformance of the service, then they will not regard it fair and will not be satisfied with the simple reperformance of the service.

H2 If customers are required to make significant additional efforts in order to achieve service recovery, then (a) the customers will have lower postcomplaint satisfaction and (b) the customer will regard the service recovery less fair.

Based on our first hypothesis, we assumed that customers do not require monetary compensation in addition to the reperformance if there is no need of them to make an effort to receive it. Based on our second hypothesis, we supposed that if there is an extra effort required from the customer to receive the flawless service, they will be less satisfied and perceive it as unfair. These two hypotheses can be modulated with regard of the interaction term: if there is an extra effort to receive the recovered service, customers will be more satisfied and will perceive it as fair if they get overcompensation. At the same time, if a customer is not required to make additional efforts, then overcompensation will actually not increase the customer's postcomplaint satisfaction and sense of fairness.

H3 Overcompensation results in significantly higher (a) postcomplaint satisfaction and (b) perceived fairness only if additional customer effort is required to attain service recovery.

The effects of overcompensation on postcomplaint customer behaviour also depend on the type of compensation (Roschk and Gelbrich 2014; Noone and Lee 2011; Noone 2012; Crisafulli and Singh 2016). One has to differentiate between cash-based and voucher-based overcompensation, which differ from each other in terms of timeliness, uncertainty and flexibility. On all three counts, cash-based overcompensation has an advantage: customers prefer instant compensation (timeliness), guaranteed compensation (uncertainty) and flexibility of use (flexibility). This is in line with the findings of Crisafulli and Singh (2016) and Noone 
and Lee (2011), who showed that customers prefer cash-based overcompensation to voucher-based overcompensation.

H4 Cash-based overcompensation leads to (a) higher postcomplaint satisfaction and to (b) a higher sense of fairness than voucher-based overcompensation, independently from the degree of additional customer effort required.

\section{Study 2: effect of customer effort on the impact of overcompensation}

The goal of this study is to test our first three hypotheses, i.e. the effects of overcompensation and additional customer effort on postcomplaint customer behaviour. We chose a scenario-based experimental methodology based on predefined scenarios. The main advantage of such an approach is that it helps respondents to identify with the situation and thus it results in more authentic customer reactions and more valid findings (Blodgett et al. 1997). Because of this, experimental methods are the most widely used tool in service recovery.

\subsection{Design}

In the experiment, we wished to examine the effects of two independent variables. The first independent variable concerned compensation, and we defined two levels in terms of the level of compensation: service recovery with simple (full) compensation $(100 \%)$ and service recovery with overcompensation (200\%). In defining the amount of overcompensation, we relied on the research results of Gelbrich et al. (2015) and Haesevoets et al. (2017), as both researches have determined 200\% overcompensation as an amount that is high enough to have either positive or negative effect on consumers.

The second independent variable relates to the concept of additional customer effort (which we identified in the exploratory research stage). Two levels are specified for this variable: significant additional customer effort and insignificant additional customer effort.

For the scenario-based experiment, we applied a $2 \times 2$ between-subject factorial design, which necessitated the creation of four scenarios based on the manipulation of the independent variables. These scenarios were randomly assigned to respondents, and it was ensured that each scenario was assigned to approximately the same number of respondents.

When developing the scenarios, we aimed to find a context which is natural enough and at the same time, lends itself to the kind of manipulation necessary for our purposes. We chose telephone subscription services, where the failed service is an erroneous monthly bill. In the high effort situation, the customer is expected to visit the customer service centre where the failure can be corrected, while, in the low effort situation, the service provider corrects the failure through telephone, without any further hassle. The level of compensation has two levels: in the full 
compensation situation the service provider pays back the erroneously charged amount, while in the overcompensation situation the service provider pays back the money plus pays the same amount once more as a compensation. The scenarios are summarized in Appendix 1.

The sample of this study consisted of 123 students from a large European university with a mean age of 24.1 , and $65 \%$ of them female and $35 \%$ male, and $72 \%$ is working besides university. We conducted our experiment within the online survey design software Qualtrics, which ensured that scenarios were allocated to respondents in a randomized fashion. The data were analysed in SPSS 23.0.

\subsection{Measures}

We defined the dependent variables in the light of the findings of previous related studies. There is a large body of literature which examines the effects of overcompensation and the findings are diverse and often contradictory; therefore, we took care to define these variables in a way which could help us to at least partially explain the somewhat paradoxical findings of earlier studies. We defined three dependent variables. To ensure the validity of the scales, we used existing scales from the literature. In order to ensure correct translation of the items, we used backtranslation (Brislin 1970) in an iterative and collaborative approach (Douglas and Craig 2007). Items of the scales were translated separately from English to Hungarian by two professionals. After reaching consensus, the items were back-translated by a third experienced researcher and after several iterations, the team reached consensus. The questionnaire was pilot tested by 10 respondents.

To measure postcomplaint satisfaction, we used a three-item scale based on Mattila and Patterson (2004) and Noone and Lee (2011): "Overall, how satisfied would you be with your customer service experience on this particular occasion?" "How satisfied would you be with the company' handling of the problem?" "Regarding this particular event, how satisfied would you be with the company's response to the problem?" (Cronbach's $\alpha=0.81$ ). To measure fairness, we used a three-item scale based on Mattila and Patterson (2004): "How fair was the employee in resolving your problem?" "How fair was the effort the company put into the problem solving?" "How fair was the service recovery you received?" (Cronbach's $\alpha=0.82$ ). Satisfaction with compensation refers in our case to satisfaction with the amount of compensation. Garrett (1999) used one item to measure compensation satisfaction that we completed to a four-item scale using scales developed by Haesoevoets et al. (2014) and Roggeveen et al. (2012) with some modification. As, in this case, the outcome that should be evaluated by respondents is the amount of money the customer received, we used the following items: "I was satisfied with the amount of compensation", "I would have expected more compensation" (reverse scale) and "In my opinion on this particular occasion the firm should have provided a higher amount of compensation" (reverse scale). "Regarding this particular event, I am satisfied with the amount of money the company provided me". After recoding the reversed items, we reached high reliability with Cronbach's $\alpha=0.85$. 
Concerning internal validity, we ran a manipulation check and found that in terms of the perceived level of effort ("How would you rate your additional effort in order to get the correct service?" 1 -I had to put a lot of effort; 5-no effort), there was a significant difference between the group means $\left(M_{\text {no effort }}=3.7 ; M_{\text {effort }}=3.11\right.$; $p<0.000$ ), which shows that the manipulation works as intended. Looking at the level of overcompensation ("Did you get (a) the amount that was incorrectly billed (b) the incorrectly billed amount plus the same amount as compensation"), the differences between groups were also significant $\left(\chi^{2}<0.001\right)$. In sum, the observed internal validity suggests that respondents had a clear perception of the different levels of the independent variables, which means that these scenarios proved to be adequate to examine the causal relationships that we were interested in. In terms of external validity, we measured the realism of the scenarios and found that respondents perceived the scenarios as realistic (means are between 4.06 and 4.73 on a 1 to 5 scale).

\subsection{Results of Study 2}

First, we discuss the results related to the satisfaction with the amount of compensation. This will be followed by a discussion of the dimensions of postcomplaint customer satisfaction and of perceived fairness. Table 1 shows the mean values of the dependent variables as a function of the levels of the independent variables.

\subsubsection{Satisfaction with the amount of compensation}

In our first hypothesis, we assumed that as long as service recovery does not involve significant additional client effort, clients will not expect monetary

Table 1 Mean values of the dependent variables for Study 2 and Study 3 (Five-point Likert scales)

\begin{tabular}{|c|c|c|c|c|}
\hline $\begin{array}{l}\text { Effort } \\
\text { needed }\end{array}$ & Compensation & $\begin{array}{l}\text { Satisfaction with the } \\
\text { amount of compensa- } \\
\text { tion }\end{array}$ & $\begin{array}{l}\text { Postcom- } \\
\text { plaint } \\
\text { satisfaction }\end{array}$ & $\begin{array}{l}\text { Perceived } \\
\text { fairness }\end{array}$ \\
\hline \multicolumn{5}{|l|}{ Study 2} \\
\hline \multirow[t]{2}{*}{ No effort } & No overcompensation & 4.29 & 4.44 & 4.41 \\
\hline & Overcompensation & 4.35 & 4.5 & 4.60 \\
\hline \multirow[t]{2}{*}{ Extra effort } & No overcompensation & 3.46 & 3.40 & 3.88 \\
\hline & Overcompensation & 4.10 & 3.97 & 4.49 \\
\hline \multicolumn{5}{|l|}{ Study 3} \\
\hline \multirow[t]{3}{*}{ No effort } & $\begin{array}{l}\text { Reperformance without overcom- } \\
\text { pensation }\end{array}$ & 3.83 & 3.10 & 4.17 \\
\hline & Voucher-based overcompensation & 3.57 & 4.04 & 4.36 \\
\hline & Cash-based overcompensation & 4.16 & 4.07 & 4.67 \\
\hline \multirow[t]{3}{*}{ Extra effort } & $\begin{array}{l}\text { Reperformance without overcom- } \\
\text { pensation }\end{array}$ & 3.09 & 2.19 & 3.47 \\
\hline & Voucher-based overcompensation & 3.88 & 3.46 & 4.32 \\
\hline & Cash-based overcompensation & 4.30 & 3.51 & 4.57 \\
\hline
\end{tabular}


compensation in addition to the flawless reperformance of the service. In order to test it, we examined the expectations of customers with regard to compensation under the different scenarios. To test the hypothesis, one-way factorial ANOVA was run, where we examined the effect of the level of compensation (independent variable) on customer satisfaction with the compensation received (dependent variable).

The numbers in Table 2 show that both of our independent variables are significant individually as well as in terms of the interaction effect $(p<0.05)$. This result allows us to investigate the moderation effect of customer effort on overcompensation. While the means for the "no effort" situation are significantly not different $\left(M_{\text {no overcomp }}=4.29\right.$ vs. $M_{\text {overcomp }}=4.35$, not significant $)$, the difference in case of "effort" situation is significant $\left(M_{\text {no overcomp }}=4.29\right.$ vs. $M_{\text {overcomp }}=4.35$; $p<0.01)$.

This indicates that as long as the customer is not required to make significant additional effort, the average compensation satisfaction values do not differ significantly between the different levels of compensation. In the light of these results, we accept Hypothesis 1. As long as customers are not required to make significant effort, they do not expect overcompensation in addition to the correct performance of the service.

Although customers do not expect higher amount of compensation, they may become more satisfied in general if they receive it. In our next analysis, we investigate the effect of customer effort and overcompensation on the satisfaction with overall service recovery.

Table 2 Main and interaction effects of Study 2

\begin{tabular}{llllll}
\hline Independent variable & $\begin{array}{l}\text { Type III sum } \\
\text { of squares }\end{array}$
\end{tabular} df $\quad$ Mean square $F \quad$ Sig $\quad$ Partial eta squared

\begin{tabular}{lcccrcc}
\hline \multicolumn{2}{l}{$\begin{array}{l}\text { Satisfaction with the amount of compensation } \\
\text { Level of effort }\end{array} \quad 8.857$} & 1 & 8.857 & 20.098 & 0.000 & 0.144 \\
Compensation & 3.724 & 1 & 3.724 & 8.451 & 0.004 & 0.066 \\
Effort $\times$ compensation & 2.460 & 1 & 2.460 & 5.582 & 0.020 & 0.045 \\
$R^{2}=0.237$ (Adjusted $R^{2}=0.218$ ) & & & & & \\
Postcomplaint satisfaction & & & & & & \\
Level of effort & 11.600 & 1 & 11.600 & 30.886 & 0.000 & 0.206 \\
Compensation & 7.166 & 1 & 7.166 & 19.080 & 0.000 & 0.138 \\
Effort $\times$ compensation & 0.259 & 1 & 0.259 & 0.689 & 0.408 & 0.006 \\
$R^{2}=0.324$ (Adjusted $R^{2}=0.307$ ) & & & & & \\
Perceived fairness & & & & & & \\
Level of effort & 3.148 & 1 & 3.148 & 10.776 & 0.001 & 0.083 \\
Compensation & 4.850 & 1 & 4.850 & 16.603 & 0.000 & 0.122 \\
Effort $\times$ compensation & 1.319 & 1 & 1.319 & 4.516 & 0.036 & 0.037 \\
$R^{2}=0.227$ (Adjusted $R^{2}=0.208$ ) & & & & & \\
\hline
\end{tabular}




\subsubsection{Postcomplaint satisfaction}

The testing of $\mathrm{H} 2$ (a) and $\mathrm{H} 3(\mathrm{a})$ means the investigation of the main and interaction effects of the independent variables on postcomplaint satisfaction. We conducted one-way factorial analysis of variance (ANOVA). The results of the F-test show that both additional effort and overcompensation have a significant main effect on postcomplaint satisfaction, while the interaction effect is not significant (Table 2). The $R^{2}$ measure indicates that additional effort and compensation, taken together, explain $32.4 \%$ of the variance of postcomplaint satisfaction.

Looking at the main effects, we find that the level of overall postcomplaint satisfaction is higher in case of no additional customer effort than it is in case of significant additional customer effort. $\left(M_{\text {no effort }}=4.33 ; M_{\text {effort }}=3.66 ; p<0.000\right)$. Based on this, we can accept Hypothesis 2(a).

As the interaction effect is not significant we have to draw the conclusion that the effect of overcompensation does not diminish with the lack of customer effort. This means that Hypothesis 3(a) has to be rejected, i.e. customers feel increased overall satisfaction in case of overcompensation even if they are not required to make extra effort.

\subsubsection{Perception of fairness}

In order to test $\mathrm{H} 2(\mathrm{~b})$ and $\mathrm{H} 3(\mathrm{~b})$, we examined the main and interaction effects of additional customer effort and the level of compensation with regard to the dependent variable, in this case, the perceived fairness of service recovery with the help of ANOVA. The $F$-test results show that both of our independent variables $(p<0.001)$ and their interaction $(p<0.05)$ have a significant effect on perceived fairness. The $R^{2}$ measure shows that a model with these two independent variables explains $23 \%$ of the variation of perceived fairness. (Table 2).

Looking at main effects, the lack of additional effort is associated with a higher level of perceived fairness $\left(M_{\text {no effort }}=4.52 ; M_{\text {effort }}=4.16 ; p<0.05\right)$. Because of this, we can accept Hypothesis 2(b).

The significant interaction term indicates that additional effort moderates the effect of overcompensation. If there is an additional customer effort, then overcompensated respondents have significantly higher perception of fairness than those respondents who received no overcompensation $\left(M_{\text {no overcomp, effort }}=3.88\right.$; $\left.M_{\text {overcomp, effort }}=4.49 ; p<0.001\right)$. In contrast, this significant relationship disappears in case of the "no effort" situation $\left(M_{\text {no overcomp, no effort }}=4.60\right.$; $M_{\text {overcomp, no effort }}=4.41$; n.s.). Because of this, Hypothesis 3(b) can be accepted. 


\section{Study 3: effect of effort and form of compensation}

In Study 3, we incorporated the testing of our fourth hypothesis, plus we wished to reinforce the results of Study 2 by replicating the hypothesis testing for the first three hypotheses in a different context.

\subsection{Design and measures}

In order to increase the robustness of the results, we selected a different context from the previous study. When developing the scenarios, we chose dry cleaning as the service and the wrinkled state of the dress as the service failure. The failure in this case was not a monetary type failure (wrong bill) but a physical type (wrinkled dress) and the recovery was not a refund but a reperformance.

Our first independent variable was similar that of the first experiment, it relates to the concept of additional customer effort and has two levels: significant additional customer effort and insignificant additional customer effort.

We took care to ensure that while the magnitude of the additional customer effort is being manipulated (in one group of scenarios, the dress will be re-ironed straight away, whereas in another group, the customer needs to come back the next day), the type of the service failure (a wrinkled dress) remains the same. In those scenarios where the service failure is fixed instantly, customers are only required to put in insignificant additional effort; whereas in those scenarios where customers are required to return later, this requires the customers to exert significant additional effort (summary of the scenarios is in Appendix 1).

In contrast to the first experiment, our second independent variable, the level of compensation, was manipulated on three levels, as we added a different format of the overcompensation, a voucher for future service. In defining the three levels above, we wished to create a situation where we can compare simple reperformance without additional compensation (100\% compensation) vs. reperformance with significant overcompensation (200\% compensation), on the one hand, and cashbased compensation vs. voucher-based compensation, on the other hand. Based on these considerations, the manipulation was designed as follows: the service failure (wrinkled dress) is redressed by (1) reperformance, (2) reperformance and full 'money back' in cash and (3) reperformance and full 'money back' in the format of a voucher redeemable at the next purchase. In the design, the three variable levels combine the effects of two factors: the level and the form of compensation. Such a variable definition is not without examples in service research, e.g. Sirianni et al. (2013) have used a similar approach in their work on customer responses to branded services.

We used a convenience sample of consumers. Our total sample size was 223 respondents, with a mean age of $29.1,77 \%$ of them female and $23 \%$ male. For this experiment, we applied a $2 \times 3$ between-subject factorial design that resulted six scenarios. Again, the scenarios were randomly assigned to respondents, and it was ensured that each scenario was assigned to approximately the same number 
of respondents. We conducted our experiment within the online survey design software Qualtrics, which ensured that scenarios were allocated to respondents in a randomized fashion. The data were analysed in SPSS 23.0.

We defined the dependent variables considering the findings of our previous study. Based on the high reliability of the scales that we used and for the sake of parsimonies, we employed one item from each scale. Perceived fairness was measured by the question "How fair do you think the way your complaint was handled?" postcomplaint customer satisfaction was measures with "In this case, how satisfied would you have left the laundry?", and satisfaction with the amount of compensation "I would have expected more compensation".

To test manipulations, we ran manipulation checks and found that in terms of the perceived level of effort, there is a significant difference between the group means, which shows that the manipulation works as intended. Looking at the level and type of overcompensation, the differences between group means are also significant. We also measured the realism of the scenarios and found that respondents perceived the scenarios as realistic (means are between 3.22 and 4.03 on a 1 to 5 scale).

\subsection{Results of Study 3}

Presentation of the result of Study 3 follows the logic of Study 2. Mean values of our dependent variables are presented in Table 1.

Table 3 Main and interaction effects of Study 3

\begin{tabular}{|c|c|c|c|c|c|c|}
\hline Independent variable & $\begin{array}{l}\text { Type III sum } \\
\text { of squares }\end{array}$ & df & Mean Square & $\mathrm{F}$ & Sig & $\begin{array}{l}\text { Partial } \\
\text { Eta } \\
\text { Squared }\end{array}$ \\
\hline \multicolumn{7}{|c|}{ Satisfaction with the amount of compensation } \\
\hline Level of effort & 0.538 & 1 & 0.538 & 0.398 & 0.529 & 0.002 \\
\hline Compensation & 23.209 & 2 & 11.605 & 8.583 & 0.000 & 0.073 \\
\hline Effort $\times$ compensation & 11.273 & 2 & 5.637 & 4.169 & 0.017 & 0.037 \\
\hline \multicolumn{7}{|c|}{$R^{2}=0.099\left(\right.$ Adjusted $\left.R^{2}=0.078\right)$} \\
\hline \multicolumn{7}{|l|}{ Postcomplaint satisfaction } \\
\hline Level of effort & 25.062 & 1 & 25.062 & 23.474 & 0.000 & 0.098 \\
\hline Compensation & 62.142 & 2 & 31.071 & 29.101 & 0.000 & 0.211 \\
\hline Effort $\times$ compensation & 1.439 & 2 & 0.720 & 0.674 & 0.511 & 0.006 \\
\hline \multicolumn{7}{|c|}{$R^{2}=0.262\left(\right.$ Adjusted $\left.R^{2}=0.245\right)$} \\
\hline \multicolumn{7}{|l|}{ Perceived fairness } \\
\hline Level of effort & 4.314 & 1 & 4.314 & 4.885 & 0.028 & 0.022 \\
\hline Compensation & 24.961 & 2 & 12.480 & 14.132 & 0.000 & 0.115 \\
\hline Effort $\times$ compensation & 4.726 & 2 & 2.363 & 2.676 & 0.071 & 0.024 \\
\hline \multicolumn{7}{|c|}{$R^{2}=0.141\left(\right.$ Adjusted $\left.R^{2}=0.122\right)$} \\
\hline
\end{tabular}




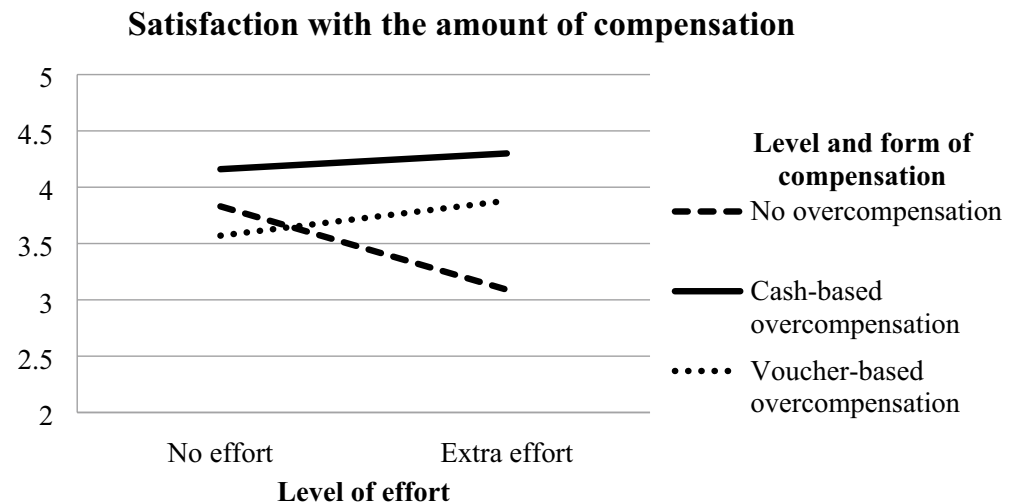

Fig. 1 Interaction effect of customer effort and compensation on the satisfaction with the amount of compensation

\subsubsection{Satisfaction with the amount of compensation}

To test our first hypothesis, we run one-way factorial ANOVA. As it is presented in Table 3 while additional customer effort does not have a significant main effect $(p=0.53)$, the interaction effect is significant $(p<0.001)$.

Based on the results that is represented in Fig. 1, we can state that albeit effort as a main effect does not impact satisfaction with the compensation amount, it moderates the effect of compensation level. This result indicates that our results should be examined separately for the two levels of effort.

Table 4 shows the results of the post hoc test of the significance of the pairwise differences between the various levels of compensation. Concerning our hypothesis,

Table 4 Post hoc test of the effect of compensation on satisfaction with the amount of compensation in relation of customer effort (Study 3)

\begin{tabular}{|c|c|c|c|c|c|c|}
\hline \multirow{2}{*}{$\begin{array}{l}\text { Level of effort } \\
\text { Level of compensation }\end{array}$} & \multicolumn{3}{|l|}{ No effort } & \multicolumn{3}{|l|}{ Extra effort } \\
\hline & $\begin{array}{l}\text { Mean dif- } \\
\text { ference }\end{array}$ & $\mathrm{SE}$ & Sign & $\begin{array}{l}\text { Mean dif- } \\
\text { ference }\end{array}$ & $\mathrm{SE}$ & Sign \\
\hline \multicolumn{7}{|l|}{ Reperformance without overcompensation } \\
\hline Cash-based overcompensation & $\mathbf{0 . 3 3}(\mathrm{ns})$ & 0.25 & 0.385 & $-1.20 * *$ & 0.28 & 0.000 \\
\hline Voucher-based overcompensation & 0.26 (ns) & 0.28 & 0.618 & $-0.78^{*}$ & 0.28 & 0.016 \\
\hline \multicolumn{7}{|l|}{ Cash-based overcompensation } \\
\hline $\begin{array}{l}\text { Reperformance without overcompen- } \\
\text { sation }\end{array}$ & $\mathbf{0 . 3 3}(\mathrm{ns})$ & 0.25 & 0.385 & $1.20 * *$ & 0.28 & 0.000 \\
\hline Voucher-based overcompensation & $0.59(n s)$ & 0.28 & 0.090 & 0.42 & 0.27 & 0.264 \\
\hline \multicolumn{7}{|l|}{ Voucher-based overcompensation } \\
\hline $\begin{array}{l}\text { Reperformance without overcompen- } \\
\text { sation }\end{array}$ & $-0.26(n s)$ & 0.28 & 0.618 & $0.78^{*}$ & 0.28 & 0.016 \\
\hline Cash-based overcompensation & $-\mathbf{0 . 5 9}(\mathrm{ns})$ & 0.28 & 0.090 & $-0.42(\mathrm{~ns})$ & 0.27 & 0.264 \\
\hline
\end{tabular}

$* p<0.05, * * p<0.01$; (ns) not significant 
one should focus on the values corresponding to "no effort" here, none of the differences are significant $\left(M_{\text {voucher }}=3.57 ; M_{\text {cash }}=4.16 M_{\text {no overcomp }}=3.83\right.$; n.s. $)$. This result reinforces the result of Study 2: as long as customers are not required to make significant additional effort, their satisfaction with the amount of compensation does not differ significantly between the different levels of compensation. To check interaction, the significant differences in case of effort situation indicates that effort moderates in effect the relationship between overcompensation and satisfaction with the amount. Based on these results, we accept Hypothesis 1, if customers are not required to make significant effort, they do not expect overcompensation in addition to the reperformance of the service.

\subsubsection{Postcomplaint satisfaction}

The results of Study 2 suggest that even if customers do not expect higher amount of compensation, they may become more satisfied in general if they receive it. To examine this assumption, we explore the effect of customer effort and overcompensation on the satisfaction with overall service recovery (H2(a) and H3(a).

At the same time, during the analysis, we test H4(a) with the investigation of the main effects of the different form of overcompensation on postcomplaint satisfaction. We conducted one-way factorial analysis of variance (ANOVA). The results of the F-test show that both additional effort and overcompensation have a significant main effect on postcomplaint satisfaction, while the interaction effect is not significant (Table 3 ). The $R^{2}$ measure indicates that additional effort and compensation, taken together, explain $24.5 \%$ of the variance of postcomplaint satisfaction. Based on the main effects, we can state that the level of postcomplaint satisfaction is higher in case of no additional customer effort than it is in case of significant additional customer effort. $\left(M_{\text {no effort }}=3.7 ; M_{\text {effort }}=3.11 ; p<0.000\right)$. Based on this, we accept Hypothesis 2(a).

In terms of levels of compensation, perhaps unsurprisingly, the lack of overcompensation is associated with the lowest level of postcomplaint satisfaction $\left(M_{\text {no comp }}=2.70\right)$, while in the case of overcompensation, no significant difference can be observed between cash-based and voucher-based compensation $\left(M_{\text {voucher }}=3.70 ; M_{\text {cash }}=3.81\right.$; not significant $)$ based on the result from the post hoc test (Appendix 2). Thus, hypothesis 4(a) has to be rejected: the form of compensation does not affect postcomplaint satisfaction.

Even though our first conclusion, based on the lack of interaction effects, was that the interaction of independent variables does not significantly affect the levels of the dependent variable, a more refined picture emerges from the post hoc Tukey test (Appendix 2). In Hypothesis 3, we hypothesized that if customers need to make additional effort, they will be more satisfied if there is some overcompensation, whereas if no additional effort is needed, than customer satisfaction will not significantly depend on whether there is overcompensation or not. The post hoc test indicates that the level of postcomplaint satisfaction is significantly different based on the different levels of compensation amount $(p<0.05)$. However, the form of compensation does not have a significant relationship with postcomplaint satisfaction on either level of the effort variable. On the contrary, the level of effort does not impact this effect at all: in both cases, satisfaction is higher if there is an overcompensation. 


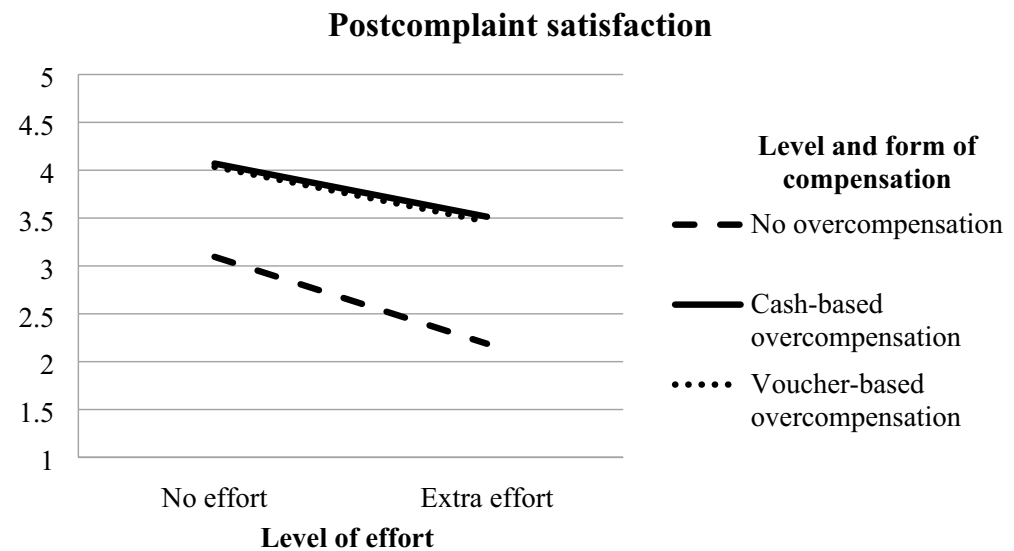

Fig. 2 Interaction effect of customer effort and compensation on postcomplaint satisfaction

At this point, it is instructive to examine Fig. 2. The horizontal axis shows the levels of additional customer effort, whereas the lines represent the level and form of overcompensation. The fact that the lines are roughly parallel clearly indicates that cash-based and voucher-based compensation leads to higher postcomplaint satisfaction even in those cases where there was insignificant additional customer effort required. This means that Hypothesis 3(a) has to be rejected, i.e. customers feel increased satisfaction in case of any form of overcompensation even if they are not required to make extra effort.

\subsubsection{Perceived fairness}

In Study 2, we found support for H2(b) and H3(b). In this subsection, we place H2(b) and H3(b) under further scrutiny, and in addition, we examine H4(b). In order to test these hypotheses, we examined the main effects of additional customer effort and the level and form of compensation with regard to the dependent variable, in this case, the perceived fairness of service recovery with the help of ANOVA. The $F$-test results show that while individually, both additional customer effort and the level and form of compensation have a significant effect on perceived fairness $(p<0.05)$, their interaction does not have a significant effect on the dependent variable-since $p$ is slightly higher than 0.05 . The $R^{2}$ measure shows that a model with these two independent variables explains $14.1 \%$ of the variation of perceived fairness. (Table 3).

Table 3 suggests that the main effects of customer effort are significant; thus, the lack of additional effort is associated with a higher level of perceived fairness $\left(M_{\text {no effort }}=4.41\right.$; $M_{\text {effort }}=4.15 ; p<0.05$ ). Based on this result, we accept Hypothesis 2(b).

In terms of the different levels and forms of compensation, our finding is that a lack of overcompensation corresponds to the lowest mean value of the dependent variable $\left(M_{\text {no comp }}=3.86\right)$, while cash-based overcompensation resulted in the highest perceived fairness, although the difference between cash-based and 
voucher-based compensation was not significant $\left(M_{\text {voucher }}=4.33 ; M_{\text {cash }}=4.63\right.$; not significant). This means that the form of overcompensation only has a negligible effect on perceived fairness, and because of this, Hypothesis 4(b) has to be rejected. In other words, the form of overcompensation (cash-based vs. voucher-based) has no influence on customers' perception of fairness of service recovery.

Although Table 3 indicates that the interaction effect is not significant, based on Fig. 3, we believe it is important to ascertain using a post hoc test whether the level of compensation (be it cash-based or voucher-based) has an effect on fairness when the level of customer effort is kept constant. As Fig. 3 proves this assumption, the level of customer effort has an effect on perceived fairness only in the case when there is no overcompensation. The results of the post hoc test (Appendix 3) indicate that if there is an additional customer effort, then overcompensated respondents have a significantly higher perception of fairness than those respondents who received no overcompensation in addition to reperformance $\left(M_{\text {no comp, effort }}=3.47\right.$; $\left.M_{\text {voucher, effort }}=4.32 ; p<0.01\right),\left(M_{\text {no comp, effort }}=3.47 ; M_{\text {cash, effort }}=4.57 ; p<0.001\right)$. Because of this, Hypothesis 3(b) can be accepted.

Based on the analysis of the two experimental studies, Table 5 summarizes the results of hypothesis testing.

Our results support that customers normally do not require additional compensation if the service failure is adequately corrected (H1). On the other hand, if they are required to make significant effort to receive the correct service that will decrease their overall satisfaction and fairness perception $(\mathrm{H} 2 \mathrm{a}, \mathrm{H} 2 \mathrm{~b})$. While the main effect of customer effort is significant, the interaction effect is significant only in the case of fairness perception. Based on the results of both studies, postcomplaint satisfaction is higher in any cases of overcompensation, i.e. even if there is no additional customer effort is required (H3a); thus, our hypothesis is not supported. On the contrary, overcompensation results higher perceived fairness only if additional customer effort is required to attain service recovery; thus, $\mathrm{H} 3 \mathrm{~b}$ is supported.

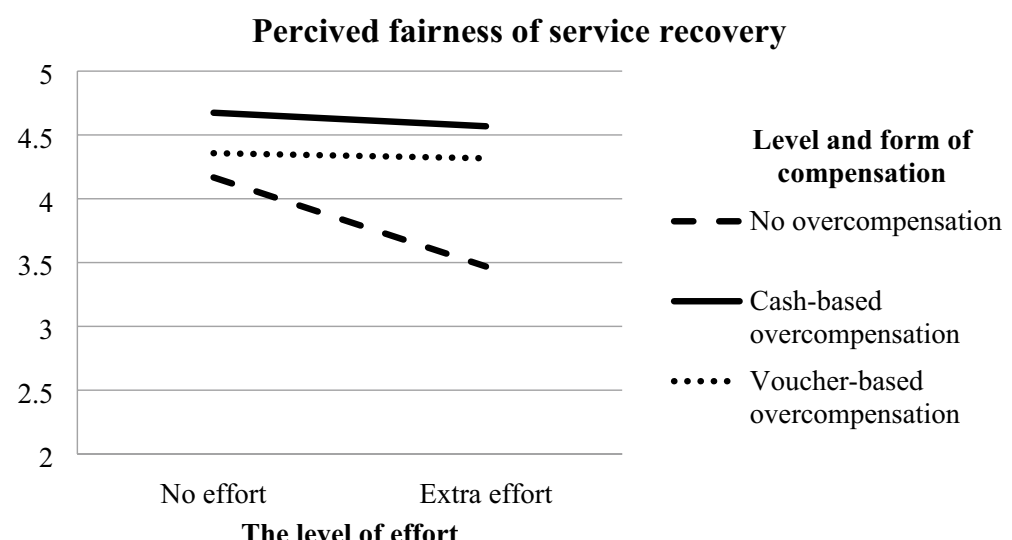

Fig. 3 Interaction effect of customer effort and compensation on perceived fairness of service recovery 


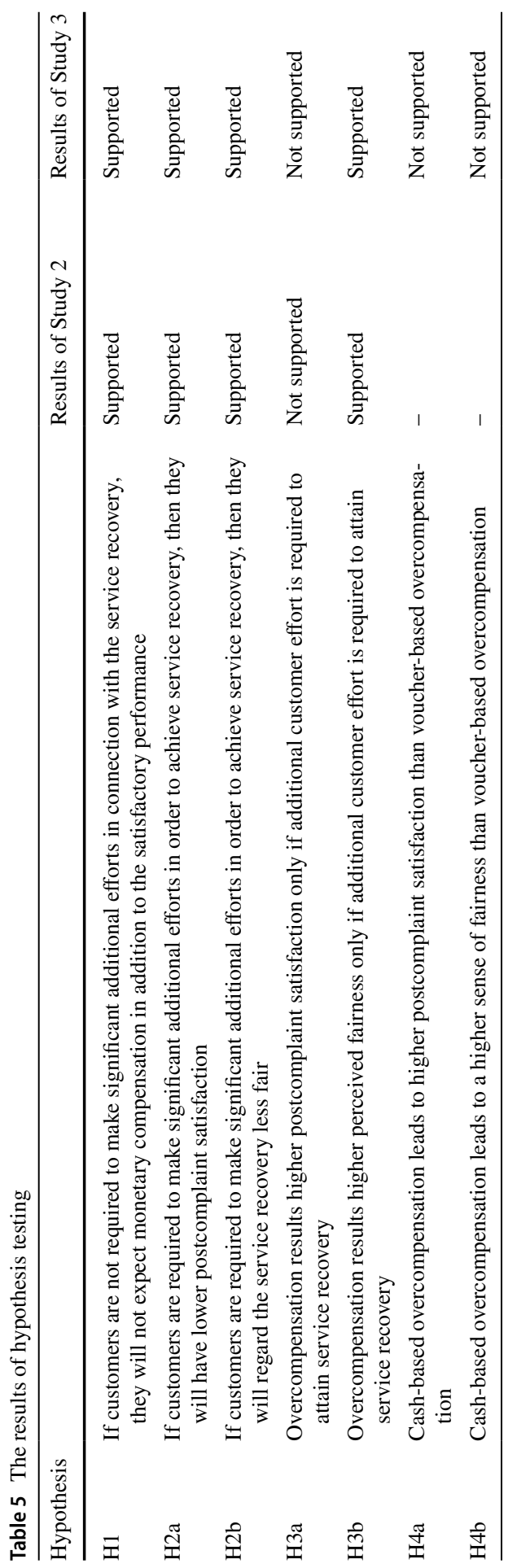


Study 3 revealed that cash-based overcompensation leads to neither higher postcomplaint satisfaction nor higher perceived fairness; therefore, $\mathrm{H} 4 \mathrm{a}$ and $\mathrm{H} 4 \mathrm{~b}$ are not supported.

\section{Conclusions and managerial implications}

This research demonstrated the effect of overcompensation on postrecovery satisfaction and fairness perception. Previous studies have explored the effect of overcompensation with contradictory results. With the help of three studies, we identified an additional factor that moderates this effect and provides a possible explanation on the diverging results.

To conclude the three studies, our main finding was the identification of a factor which we recognized in the course of the interview-based explorative research stage, i.e. additional customer effort. Based on the interviews, we proposed that if the correction of a service failure entailed significant additional costs for the customer (whether of temporal, material or emotional nature), then most customers considered it appropriate or fair to receive overcompensation (i.e. compensation which exceeds the direct economic loss suffered).

In two experimental studies, we tested the hypotheses based on the interviews. Both studies applied scenario-based experimental design though in different settings (telecommunication services and laundry). The results of the two studies increased robustness and validity of our findings.

The results confirmed our hypotheses that additional customer effort not only had a main effect on postcomplaint satisfaction and on postcomplaint perception of fairness, but on the other hand it moderated the effect of overcompensation on compensation satisfaction and fairness perception. The implication is that if service recovery necessitates additional effort from the customer, be it physical, temporal or monetary, then the customer will expect to be offered some kind of overcompensation in addition to the mere correction of the service.

From the perspective of satisfaction, these results indicated that customers perceived a compensation satisfying only if the organization considered (and compensated for) all the costs which arise from the service failure and subsequent service recovery. In the light of this, it is an important finding that as long as service recovery did not entail significant client effort, clients did not expect overcompensation in addition to failure correction. However, if they received overcompensation, this increased their postcomplaint satisfaction independently of the effort level.

In addition to looking at the effects of additional customer efforts, we also examined the role of the different forms of compensation, a variable identified as relevant in much of the available literature. However, our findings indicated that it did not have a significant effect on either satisfaction or the perception of fairness. Whether overcompensation was offered in cash or voucher, format did not play a role. 
Our findings suggest that in order to ensure a perception of fairness in those service recovery situations which entail significant additional customer effort, organizations are advised to offer overcompensation in addition to merely correcting or reperforming the flawed service. However, the form of overcompensation does not have a significant effect on either satisfaction or perception of fairness. Organization's choice between these formats should be guided by other principles, such as costeffectiveness or the encouragement of repurchase and customer loyalty. Although we assume that customers do not specifically require a significant overcompensation in such cases, it is still possible that some overcompensation additional to the reperformance may increase their postcomplaint satisfaction.

While we believe that our results are valid within the scenario-based experimental methodological framework, we also think that it will be important to augment these results with data from different methodological approaches such as critical incident technique. Also, we have only been looking at two levels of overcompensation: no overcompensation vs. $100 \%$ overcompensation-it would be interesting to examine a more fine-grained scale in order to identify the exact degree of overcompensation which is profit-maximizing for the organization-a value which probably also depends on the level of additional customer effort. In the current study, additional customer effort was operationalized as an amalgam of various types of cost (temporal and monetary) - however, it might be instructive to see to what extent these different types have different effects on overcompensation expectations and on postcomplaint satisfaction as a function of overcompensation. It is possible that if the only costs are of a temporal nature, customers will be satisfied with reperformance and an apology, compared to some sort of monetary overcompensation. It would be also fruitful to determine if monetary costs lead to a higher expectation of monetary compensation compared to emotional costs, and if so, how significant is the difference. The study of these questions will enable us to provide further help to service companies with regard to the selection of the optimal compensation level in cases of service failure. Another natural limitation of our quantitative study concerns the actual service situations selected. For simplicity, in each scenario, we focused on one service, a laundry service failure and a telecommunication. On the one hand, this increased validity but on the other hand, other service scenarios should also be examined to see to what extent our findings concerning the effects of customer effort and compensation on postcomplaint behaviour carry over to different service environments. Further research into these questions is critical in order to help organizations calibrate the optimal level of compensation.

Acknowledgements Open access funding provided by Corvinus University of Budapest (BCE).

Open Access This article is licensed under a Creative Commons Attribution 4.0 International License, which permits use, sharing, adaptation, distribution and reproduction in any medium or format, as long as you give appropriate credit to the original author(s) and the source, provide a link to the Creative Commons licence, and indicate if changes were made. The images or other third party material in this article are included in the article's Creative Commons licence, unless indicated otherwise in a credit line to the material. If material is not included in the article's Creative Commons licence and your intended use is not permitted by statutory regulation or exceeds the permitted use, you will need to obtain permission directly from the copyright holder. To view a copy of this licence, visit http://creativecommons.org/licen ses/by/4.0/. 


\section{Appendix 1 Summary of the scenarios}

\section{Study 2}

You bought a new mobile subscription with a flat rate pricing scheme. After getting the first monthly bill, you realize that the amount the company billed is double of your expected monthly rate. You call the call centre right away and try to find out the reason for the wrong bill.

The operator understands the problem and after a short checking in the system acknowledges the failure and apologizes for it. She assures you that the original scheme will be fixed in the system,

1.a. ... and she changes it right away.

1.b. ... but to correct the problem you have to visit the customer service centre. You go to the customer service the next day where after quite a long wait the customer service rep corrects the failure and asks again for your apology.

She assures you that the company will pay back the amount charged erroneously,

2.a. ... in this way you will be fully reimbursed.

2.b. ... plus to compensate for the inconvenience the company offers you the first month free of charge.

\section{Study 3}

You bought an exquisite high-priced dress not long ago, which you would like to be cleaned now as there is a huge stain on it. Since the dress is very delicate, you bring it to the laundry. The employee tells you to come back next day for the clean dress.

When the next day you go to the laundry and receive the dress, you realize that it was not ironed properly and there are several wrinkles on it. You show it to the lady in the laundry and tell her your problem. She admits right away the problem, apologizes and tells you.

1.a. ...to wait a few minutes, they are going to iron it right away.

1.b. ...to come back tomorrow, they will iron it again by that time.

2.a. (says nothing more)

2.b. To compensate for the inconvenience, she offers you not to pay for the service.

2.c. To compensate for the inconvenience, she offers you a voucher in the amount of the service that you can use next time. 


\section{Appendix 2}

\section{See Table 6.}

Table 6 Post hoc test of the effect of compensation on satisfaction with recovery (Study 3)

\begin{tabular}{|c|c|c|c|c|c|c|}
\hline \multirow{2}{*}{$\begin{array}{l}\text { Level of effort } \\
\text { Level of compensation }\end{array}$} & \multicolumn{3}{|l|}{ No effort } & \multicolumn{3}{|l|}{ Extra effort } \\
\hline & Mean difference & SE & Sig & Mean difference & SE & Sig \\
\hline \multicolumn{7}{|l|}{$\begin{array}{l}\text { Reperformance without overcompensa- } \\
\text { tion }\end{array}$} \\
\hline Cash-based overcompensation & -0.97 & 0.227 & 0.000 & -1.32 & 0.24 & 0.000 \\
\hline Voucher-based overcompensation & -0.94 & 0.22 & 0.001 & -1.27 & 0.23 & 0.000 \\
\hline \multicolumn{7}{|l|}{ Cash-based overcompensation } \\
\hline $\begin{array}{l}\text { Reperformance without overcompen- } \\
\text { sation }\end{array}$ & 0.97 & 0.22 & 0.000 & 1.32 & 0.24 & 0.000 \\
\hline Voucher-based overcompensation & 0.03 & 0.25 & 0.990 & 0.050 & 0.23 & 0.974 \\
\hline \multicolumn{7}{|l|}{ Voucher-based overcompensation } \\
\hline $\begin{array}{l}\text { Reperformance without overcompen- } \\
\text { sation }\end{array}$ & 0.94 & 0.25 & 0.001 & 1.27 & 0.23 & 0.000 \\
\hline Cash-based overcompensation & -0.03 & 0.25 & 0.990 & -0.05 & 0.23 & 0.974 \\
\hline
\end{tabular}

\section{Appendix 3}

See Table 7.

Table 7 Post hoc test of the effect of compensation on perceived fairness in relation of customer effort (Study 3)

\begin{tabular}{|c|c|c|c|c|c|c|}
\hline \multirow{2}{*}{$\begin{array}{l}\text { Level of effort } \\
\text { Level of compensation }\end{array}$} & \multicolumn{3}{|l|}{ No effort } & \multicolumn{3}{|l|}{ Extra effort } \\
\hline & Mean difference & SE & Sig & Mean difference & SE & Sig \\
\hline \multicolumn{7}{|l|}{$\begin{array}{l}\text { Reperformance without overcompensa- } \\
\text { tion }\end{array}$} \\
\hline Cash-based overcompensation & -0.51 & 0.21 & 0.041 & -1.10 & 0.22 & 0.000 \\
\hline Voucher-based overcompensation & -0.19 & 0.23 & 0.691 & -0.85 & 0.22 & 0.001 \\
\hline \multicolumn{7}{|l|}{ Cash-based overcompensation } \\
\hline $\begin{array}{l}\text { Reperformance without overcompen- } \\
\text { sation }\end{array}$ & 0.51 & 0.21 & 0.041 & 1.10 & 0.22 & 0.000 \\
\hline Voucher-based overcompensation & 0.32 & 0.23 & 0.359 & 0.25 & 0.21 & 0.461 \\
\hline \multicolumn{7}{|l|}{ Voucher-based overcompensation } \\
\hline $\begin{array}{l}\text { Reperformance without overcompen- } \\
\text { sation }\end{array}$ & 0.19 & 0.23 & 0.691 & 0.85 & 0.22 & 0.001 \\
\hline Cash-based overcompensation & -0.32 & 0.23 & 0.359 & -0.25 & 0.21 & 0.461 \\
\hline
\end{tabular}




\section{References}

Blodgett JG, Hill DJ, Tax S (1997) The effects of distributive, procedural, and interactional justice on postcomplaint behavior. J Retail 73(2):185-210

Brislin RW (1970) Back-translation for cross-cultural research. J Cross Cult Psychol 1(3):185-216

Cambra-Fierro J, Melero-Polo I, Sese FJ (2015) Does the nature of the relationship really matter? An analysis of the roles of loyalty and involvement in service recovery processes. Service Business 9(2):297-320

Cambra-Fierro J, Melero-Polo I, Sese FJ (2016) Can complaint-handling efforts promote customer engagement? Serv Bus 10(4):847-866

Charmaz K (2014[2006]) Constructing grounded theory: a practical guide through qualitative analysis, 1st, 2nd ed. Sage: Thousand Oaks, New Delhi

Charmaz K (2000) Grounded theory objectivist and constructivist method. In: Denzin N, Lincoln Y (Eds) Handbook of qualitative research. Sage: California, pp 509-536

Chen W, Lee HC (2018) How to explain service failure? Impact of justifications. Serv Bus 12(2):331-356

Chen T, Ma K, Bian X, Zheng C, Devlin J (2018) Is high recovery more effective than expected recovery in addressing service failure? A moral judgment perspective. J Bus Res 82:1-9

Cheung MF, To WM (2017) The effect of organizational responses to service failures on customer satisfaction perception. Serv Bus 11(4):767-784

Choi B, Choi BJ (2014) The effects of perceived service recovery justice on customer affection, loyalty, and word-of-mouth. Eur J Mark 48(1/2):108-131

Crisafulli B, Singh J (2016) Service guarantee as a recovery strategy: The impact of guarantee terms on perceived justice and firm motives. J Serv Manag 27(2):117-143

Davidow M (2003) Organizational responses to customer complaints: what works and what doesn't. J Serv Res 5(3):225-250

del Río-Lanza AB, Vázquez-Casielles R, Díaz-Martín AM (2009) Satisfaction with service recovery: Perceived justice and emotional responses. J Bus Res 62(8):775-781

Denzin Y, Lincoln YS (2011) The SAGE handbook of qualitative research, 4th edn. Sage, Thousand Oaks

Douglas SP, Craig CS (2007) Collaborative and iterative translation: an alternative approach to back translation. J Int Market 15(1):30-43

Estelami H, Maeyer PD (2002) Customer reactions to service provider overgenerosity. J Serv Res 4(3):205-216

Garrett DE (1999) The effectiveness of compensation given to complaining consumers: is more better? J Consum Satisf Dissatisf Complain Behav 12:26-34

Gelbrich K, Roschk H (2011) Do complainants appreciate overcompensation? A meta-analysis on the effect of simple compensation vs overcompensation on post-complaint satisfaction. Market Lett 22(1):31-47

Gelbrich K, Gäthke J, Grégoire Y (2015) How much compensation should a firm offer for a flawed service? An examination of the nonlinear effects of compensation on satisfaction. J Serv Res 18(1):107-123

Gelbrich K, Gäthke J, Grégoire Y (2016) How a firm's best versus normal customers react to compensation after a service failure. J Bus Res 69:4331-4339

Glaser BG (1992) Basics of grounded theory analysis. The Sociology Press, Mill Valley

Haesevoets T, Hiel AV, Folmer CR, Cremer DD (2014) What money can't buy: The psychology of financial overcompensation. J Econ Psychol 42:83-95

Haesevoets T, Hiel AV, Pandelaere M, Bostyn DH, Cremer DD (2017) How much compensation is too much? An investigation of the effectiveness of financial overcompensation as a means to enhance customer loyalty. Judgm Decis Mak 12(2):183-197

Kim N, Ulgado FM (2012) The effect of on-the-spot versus delayed compensation: the moderating role of failure severity. J Serv Mark 26(3):158-167

Mannaa M, Chaudhry B (2013) Role of justice in the complaint handling setting: scenario-based experiment study. Acad Contemp Res J 2(4):131-151

Mattila AS, Patterson PG (2004) Service recovery and fairness perceptions in collectivist and individualist contexts. J Serv Res 6(4):336-346 
Maxham JG III (2001) Service recovery's influence on consumer satisfaction, positive word-of-mouth, and purchase intentions. J Bus Res 54(1):11-24

Maxham JG III, Netemeyer RG (2002) A longitudinal study of complaining customers' evaluations of multiple service failures and recovery efforts. J Market 66(4):57-71

McColl-Kennedy JR, Sparks BA (2003) Application of fairness theory to service, failures and service recovery. J Serv Res 5(3):251-266

McCollough MA, Berry LL, Yadav MS (2000) An empirical investigation of customer satisfaction after service failure and recovery. J Serv Res 3(2):121-137

Noone BM (2012) Overcompensating for severe service failure: perceived fairness and effect on negative word-of-mouth intent. J Serv Mark 26(5):342-351

Noone BM, Lee CH (2011) Hotel overbooking: the effect of overcompensation on customers' reactions to denied service. J Hosp Tour Res 35(3):334-357

Roggeveen AL, Tsiros M, Grewal D (2012) Understanding the co-creation effect: when does collaborating with customers provide a lift to service recovery? J Acad Mark Sci 40(6):771-790

Roschk H, Gelbrich K (2014) Identifying appropriate compensation types for service failures: a metaanalytic and experimental analysis. J Serv Res 17(2):195-211

Sirianni NJ, Bitner MJ, Brown SW, Mandel N (2013) Branded service encounters: strategically aligning employee behavior with the brand positioning. J Market 77(6):108-123

Smith AK, Bolton RN, Wagner J (1999) A model of customer satisfaction with service encounters involving failure and recovery. J Mark Res 36(3):356-372

Standop D, Grunwald G (2009) How to solve product-harm crises in retailing? Empirical insights from service recovery and negative publicity research. Int J Retail Distrib Manag 37(11):915-932

Strauss A, Corbin J (1990) Basics of qualitative research: grounded theory procedures and techniques. Sage, Newbury Park, CA

Tang X, En-Chung C, Xing H, Meng Z (2018) Timing and compensation strategies in service recovery. J Serv Mark 32(6):755-766

Tax SS, Brown SW, Chandrashekaran M (1998) Customer evaluations of service complaint experiences: implications for relationship marketing. J Mark 62(2):60-76

Tektas OO (2017) Perceived justice and post-recovery satisfaction in banking service failures: do commitment types matter? Serv Bus 11(4):851-870

Wertz FJ, Charmaz K, McMullen LJ et al (2011) Five ways of doing qualitative analysis: phenomenological psychology, grounded theory, discourse analysis, narrative research, and intuitive inquiry. Guilford, New York

Wirtz J, Mattila AS (2004) Consumer responses to compensation, speed of recovery and apology after a service failure. Int J Serv Ind Manag 15(2):150-166

Zaubermann G (2003) The intertemporal dynamics of consumer lock-in. J Consum Res 30:405-419

Publisher's Note Springer Nature remains neutral with regard to jurisdictional claims in published maps and institutional affiliations. 